\title{
Functions of microRNA-143 in the apoptosis, invasion and migration of nasopharyngeal carcinoma
}

\author{
JIN-HUI CHEN, RUI YANG, WEI ZHANG and YONG-PING WANG \\ Department of Otorhinolaryngology, Head and Neck Surgery, Renmin Hospital of Wuhan University, \\ Wuhan, Hubei 430060, P.R. China
}

Received August 25, 2015; Accepted September 13, 2016

DOI: $10.3892 /$ etm.2016.3847

\begin{abstract}
Nasopharyngeal carcinoma (NPC) is a common cancer characterized by poor prognosis in areas of Southern China where it is endemic. microRNAs (miRNAs) are a class of naturally occurring small noncoding RNAs, some of which contribute to the initiation and development of cancer. The current study was designed to examine the expression level of miR-143 in NPC tissues. The potential functional targets of miR-143 involved in tumor apoptosis, invasion and migration were also investigated. Reverse transcription-quantitative polymerase chain reaction was used to evaluate the expression levels of miR-143 in clinical NPC specimens. Western blotting was used to explore the expression levels of extracellular signal regulated kinase (ERK)-5, Kirsten rat sarcoma viral oncogene homolog (KRAS), caspase 3 and B-cell lymphoma 2 (Bcl-2) in CNE-2Z cells following transfection with miR-143. Significantly decreased expression levels of miR-143 were observed in NPC tissues in comparison with matched normal nasopharyngeal tissues. Moreover, negative associations of miR-143 with tumor invasion depth, as well as lymph node metastasis were found. The enforced expression of miR-143 induced NPC cell apoptosis in addition to the suppression of growth, migration and invasion. The functions of miR-143 in NPC are mediated, at least in part, by the inhibition of ERK-5 activity and promotion of caspase 3 and KRAS expression. These findings suggest that miR-143 may function as a tumor suppressor in the development and progression of NPC.
\end{abstract}

\section{Introduction}

Nasopharyngeal carcinoma (NPC) is a rare malignancy in most parts of the world, but occurs with a high prevalence in

Correspondence to: Professor Jin-Hui Chen, Department of Otorhinolaryngology, Head and Neck Surgery, Renmin Hospital of Wuhan University, 238 Jiefang Road, Wuchang, Wuhan, Hubei 430060, P.R. China

E-mail: chenjhphd@163.com

Key words: nasopharyngeal carcinoma, miR-143, apoptosis, metastasis, tumor suppressor areas of Southern China, Southeast Asia and North Africa where it comprises a substantial health burden (1-3). NPC is a highly malignant tumor because of its frequent metastasis and poor prognosis $(2,4)$. Therefore, it is important to gain a better understanding of the molecular mechanisms of NPC invasion and migration in order to improve the prognosis of patients with NPC.

MicroRNAs (miRNAs) are an evolutionarily conserved family of small non-coding RNA molecules, comprising $\sim 22$ nucleotides, that are found in plants, animals and some viruses and function to silence RNA and suppress gene expression at a post-transcriptional level. They are increasingly considered as important gene expression regulators in multiple cellular progresses, including tumorigenesis and metastasis in variety of tumors (5). In NPC, a number of miRNAs have been reported to serve as oncogenes or suppressor genes in the development and progression of NPC, including miR-10b, which was shown to promote the metastasis of NPC cells in previous studies (6-8). However, miR-200a has been reported to be downregulated in NPC, and to act as an inhibitor of migration and invasion (9).

Several reports have suggested that miR-143 is downregulated in many types of cancers, including colorectal, gastric, osteosarcoma, bladder and epithelial cancers (10-14). Upregulated miR-143 transcribed by nuclear factor- $\kappa \mathrm{B}$ has been reported to increase the metastasis of hepatocellular carcinoma by targeting fibronectin expression (15). In addition, miR-143 has been found to be significantly downregulated in clinical samples from NPC patients, and to inhibit NPC proliferation in vivo and in vitro (16). However, the downregulation of miR-143 in NPC tissues and cell lines requires further investigation and the correlations of miR-143 with invasion and migration are not yet known.

In the present study, the aim was to investigate the following: i) Whether miR-143 expression is changed in NPC tissues and cell lines; ii) the role of miR-143 in tumor proliferation, invasion and migration; and iii) the functional target(s) of miR-143 involved in tumor growth, invasion and migration.

\section{Materials and methods}

Clinical specimens and cell culture. Paired human NPC tissues and matched normal tissues were collected from 40 patients (15 women and 25 men; age range, 44-85 years; median age, 
71 years), who had undergone standard surgical procedures in the Renmin Hospital of Wuhan University (Wuchang, China), with the informed consent of the patients. The tissue samples were collected from February 2010 to October 2013. Parts of tissue samples were immediately snap-frozen in liquid nitrogen, and sections were fixed in formalin for histological examination. The disease stage and lymph node metastasis were determined via the pathological examination of histology slides in the patient cohort. The experimental protocols were approved by the Institutional Review Committees of Wuhan University.

Human NPC cell lines CNE-1, CNE-2Z and NP69, obtained from the Cell Bank of Academia Sinica (Shanghai, China), were cultured in RPMI-1640 medium supplemented with $10 \%$ fetal bovine serum (FBS; both Invitrogen; Thermo Fisher Scientific, Inc., Waltham, MA, USA) and $1 \%$ penicillin-streptomycin solution in a $37^{\circ} \mathrm{C}$ incubator containing $5 \% \mathrm{CO}_{2}$.

RNA isolation and reverse transcription-quantitative polymerase chain reaction ( $R T-q P C R)$. Total RNA was obtained from NPCs, normal tissue samples and cell lines using TRIzol reagent (Invitrogen; Thermo Fisher Scientific, Inc.), according to the manufacturer's instructions. Complementary DNA was synthesized from the RNA using a cDNA Synthesis kit (Thermo Fisher Scientific, Inc.). The RT-qPCR reactions were run on a 7500 Real-Time PCR machine (Applied Biosystems; Thermo Fisher Scientific, Inc.). Maxima SYBR Green/ROX qPCR Master mix (K0223; Finnzymes; Thermo Fisher Scientific, Inc.) was used, according to the manufacturer's protocol. The qPCR cycling conditions were as follows: $95^{\circ} \mathrm{C}$ for $10 \mathrm{~min}$, followed by 40 cycles at $95^{\circ} \mathrm{C}$ for $15 \mathrm{sec}$ and $60^{\circ} \mathrm{C}$ for $45 \mathrm{sec}$, and a final extension step of $95^{\circ} \mathrm{C}$ for $15 \mathrm{sec}, 60^{\circ} \mathrm{C}$ for $1 \mathrm{~min}, 95^{\circ} \mathrm{C}$ for $15 \mathrm{sec}$ and $60^{\circ} \mathrm{C}$ for $15 \mathrm{sec}$. The miRNA expression level was normalized to the expression level of U6 small nuclear RNA (RNU6B). Primers used for hsa-miR-143 were purchased from Applied Biosystems. Their sequences were as follows: hsa-miR-143, forward: 5'-ACACTCCAG CTGGGGGTGCAGTGCTGCATC-3' and reverse: 5'-CTC AACTGGTGTCGTGGAGTCGGCAATTCAGTTGAGACC AGA-3'; RNU6B, forward: 5'-CTTCGGCAGCACATATAC-3' and reverse: 5'-GGCCATGCTAATCTTCTC-3'. All reactions were performed in triplicate and included a negative control lacking cDNA. The relative expression values were calculated using the $\Delta \Delta \mathrm{Cq}$ method (17).

Transfection. CNE-1, CNE-2Z and NP69 cells were transfected with double stranded synthetic syn-hsa-miR-143 mimics and scrambled controls (Thermo Fisher Scientific, Inc.) using Lipofectamine 2000 (Thermo Fisher Scientific, Inc.) according to the manufacturer's protocol for overexpression. Briefly, $\sim 1.5 \times 10^{5}$ cells were seeded and cultured in 6 -well plates the day prior to transfection. miRNA mimic with a concentration of $1,2.5$ or $5 \mathrm{nM}$ and scrambled controls (NC) were each transfected into CNE-1 and CNE-2Z cells. After transfection for $72 \mathrm{~h}$, the functions of the cells were examined. All groups were performed in triplicate.

Cell viability and cell apoptosis assay. CNE-1 and CNE-2Z cells transfected with miRNA mimics or scrambled controls were harvested at 24, 48 and $72 \mathrm{~h}$ after transfection and seeded in 96 -well plates $\left(5 \times 10^{3}\right.$ cells/well). Then, $10 \mu \mathrm{l}$ Cell
Counting kit-8 (CCK-8) assay solution (Dojindo Molecular Technologies, Inc., Kumamoto, Japan) was added to each well and the plate was incubated for $1 \mathrm{~h}$ at $37^{\circ} \mathrm{C}$. The absorbance was then measured at $450 \mathrm{~nm}$ using a microplate reader.

For the cell apoptosis assay, the transfected CNE-1 and CNE-2Z cells were seeded in 6 -well plates $\left(5 \times 10^{5}\right.$ cells). At $72 \mathrm{~h}$ after transfection the cells were harvested and stained with Annexin V-fluorescein isothiocyanate (BD Biosciences, Franklin Lakes, NJ, USA) and propidium iodide (BD Biosciences) for $15 \mathrm{~min}$ in the dark at room temperature followed by flow cytometric analysis using a BD Accuri C6 Flow Cytometer equipped with software version 1.0.264.21 (BD Biosciences, San Diego, CA, USA).

In vitro invasion and migration assays. The $\mathrm{CNE}-2 \mathrm{Z}$ cell line, which has high invasiveness, was selected for analysis using in vitro migration and invasion assays. In Transwell migration and invasion assays, cells were serum-starved for $24 \mathrm{~h}$, following which $1 \times 10^{4}$ transfected cells in serum-free RPMI-1640 were seeded into the upper well of the Transwell chamber, onto non-coated or Matrigel-coated membrane (BD Biosciences), respectively. RPMI-1640 medium supplemented with $10 \%$ FBS $(750 \mu \mathrm{l})$ was added to the lower well of the chamber. The chamber was maintained at $37^{\circ} \mathrm{C}$ in a $5 \% \mathrm{CO}_{2}$ incubator for $48 \mathrm{~h}$. The uninvaded/unmigrated cells were removed with a cotton swab. The cells on the lower surface of the membrane were then fixed with $4 \%$ paraformaldehyde $\left(25^{\circ} \mathrm{C}\right.$ for $\left.10 \mathrm{~min}\right)$, stained with $0.5 \%$ crystal violet $\left(25^{\circ} \mathrm{C}\right.$ for $30 \mathrm{~min}$ ) and then counted.

Protein extraction and western blotting. Transfected CNE-2Z cells were harvested and lysed on ice for $30 \mathrm{~min}$ in radioimmunoprecipitation assay buffer (Beyotime Institute of Biotechnology, Haimen, China) supplemented with $1 \mathrm{mM}$ phenylmethylsulfonyl fluoride. Total protein extracts were separated by electrophoresis on $8 \%$ SDS-PAGE gels and transferred to polyvinylidene fluoride membranes. Primary antibodies against extracellular-signal-regulated kinase 5 (ERK5; 1:1,000; cat. no. 12950; Cell Signaling Technology, Inc., Danvers, MA, USA), B-cell lymphoma 2 (Bcl-2; 1:1,000; cat. no. 3498; Cell Signaling Technology, Inc.), Kirsten rat sarcoma viral oncogene homolog (KRAS; 1:1,000; cat. no. 3339; Cell Signaling Technology, Inc.), caspase 3 (1:1,000; cat. no. 9662; Cell Signaling Technology, Inc.) and $\beta$-actin (1:500; cat. no. sc-47778; Santa Cruz Biotechnology, Inc., Dallas, TX, USA) were incubated with the membranes at $4^{\circ} \mathrm{C}$ overnight. After washing with PBS three times, the membranes were incubated with the secondary antibodies horseradish peroxidase-conjugated goat anti-rabbit $\operatorname{IgG}(1,000$; cat. no. A0208; Beyotime Institute of Biotechnology) and goat anti-mouse $\operatorname{IgG}$ (1:1,000; cat. no. A0216; Beyotime Institute of Biotechnology) for $1 \mathrm{~h}$ at $37^{\circ} \mathrm{C}$. The membranes were washed again, and the antigen-antibody reaction was visualized using an Amersham ECL detection system (GE Healthcare Life Sciences, Chalfont, UK). Protein levels were determined by assesing the signal intensity of the bands using ImageJ 1.46 software (National Institutes of Health, Bethesda, MD, USA).

Statistical analysis. Data are presented as the mean \pm standard deviation. The paired, two-tailed Student's t-test was used to 
A

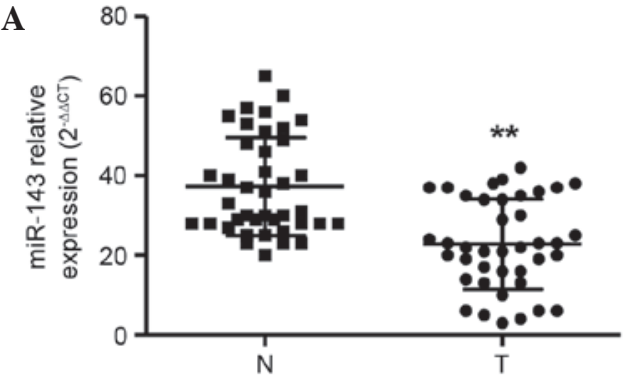

C

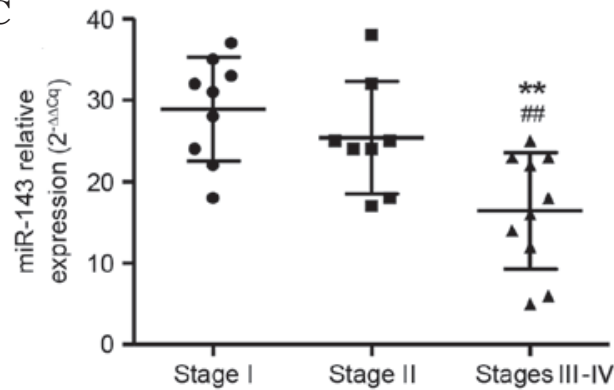

B

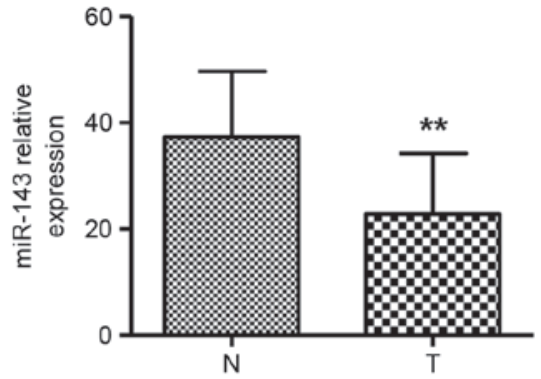

D

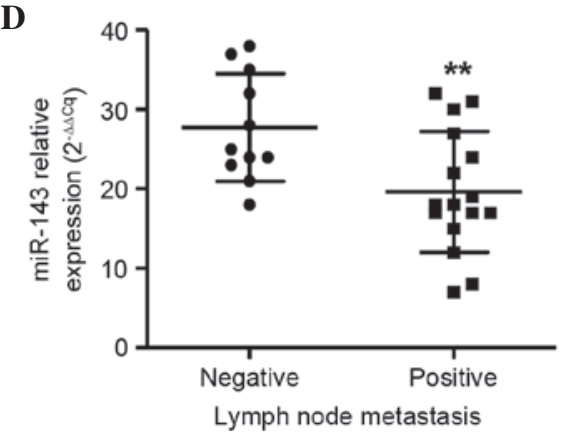

Figure 1. miR-143 expression levels are downregulated in cancer tissues and correlated with NPC clinical stages (A) Relative expression levels of miR-143 in 40 clinical samples of NPC and matched normal tissue samples were analyzed by reverse transcription-quantitative polymerase chain reaction and normalized to U6 expression. (B) Mean expression level plus standard deviation of miR-143 in 40 NPCs compared with matched normal tissue samples. Values represent the means of three replicates. ${ }^{* *} \mathrm{P}<0.01$ vs. the $\mathrm{N}$ group. (C) Relative expression levels of miR-143 in NPC of different stages. ${ }^{* *} \mathrm{P}<0.01$ vs. stage I; ${ }^{\# \# P<0.01 ~ v s . ~}$ stage II. (D) Relative expression levels of miR-143 in NPCs with and without lymph node metastasis. ${ }^{* *} \mathrm{P}<0.01$ vs. negative lymph node metastasis status. NPC, nasopharyngeal carcinoma; $\mathrm{T}$, tumor tissue; $\mathrm{N}$, normal adjacent tissue.

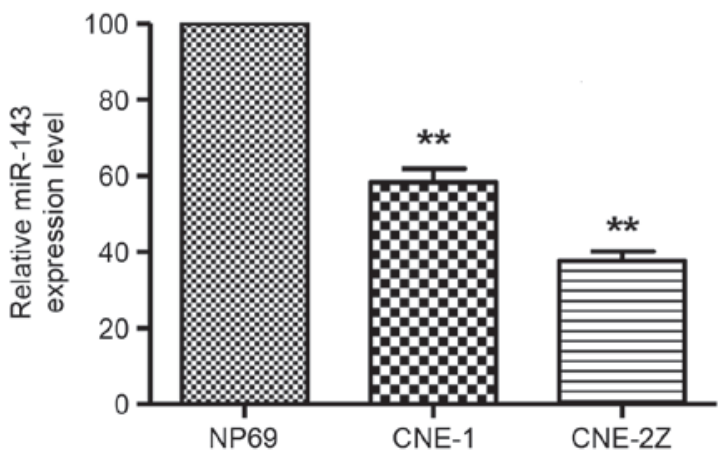

Figure 2. miR-143 expression levels in non-NPC cells (NP69) and two NPC cell lines. Quantitative polymerase chain reaction revealed that the miR-143 expression level was significantly decreased in the two NPC cell lines compared with the NP69 cell line. ${ }^{* *} \mathrm{P}<0.01$ vs. NP69 cells. NPC, nasopharyngeal carcinoma.

analyze the significance of differences between groups. $\mathrm{P}<0.05$ was considered to indicate a statistically significant difference.

\section{Results}

miR-143 is downregulated in NPC tissues. To investigate the role of miR-143 in NPC tumorigenosis, the expression levels of miR-143 in 40 clinical samples of NPC and matched normal tissue samples were first evaluated by TaqMan qPCR (Fig. 1A). RNU6B was used as an internal standard. A significant downregulation of miR-143 expression was found in NPCs in comparison with normal tissue samples $(\mathrm{P}<0.01)$. The mean level of miR-143 in NPCs was decreased to $~ 51.6 \%$ of that in the matched normal tissue samples (Fig. 1B). The miR-143 expression levels were also compared among NPC samples of different stages. The number of samples of each stage was as follows: Stage I $(n=12)$, stage II $(n=12)$ and stages III-IV $(n=16)$ The miR-143 expression levels in cancer tissues were negatively correlated with the stage of the NPC patients. The early stages I and II showed significantly higher miR-143 expression levels than those in the late stages III and IV $(\mathrm{P}<0.01$; Fig. $1 \mathrm{C})$. Furthermore, miR-143 expression levels were also compared among NPC samples with $(n=24)$ and without $(n=16)$ lymph node metastasis. miR-143 levels were markedly lower in the patients with lymph node metastasis than in the patients without lymph node metastasis (Fig. 1D), which is consistent with the aforementioned result, since lymph node metastasis commonly occurs in stages III and IV, but not I and II.

miR-143 is downregulated in NPC cells and involved in cell proliferation and apoptosis. In the two NPC cell lines, miR-143 was substantially downregulated compared with that in the non-malignant nasopharynx cell line NP69 (P<0.01; Fig. 2). The effects of miR-143 on the NPC cell lines were then examined in vitro by transfection. As shown in Fig. $3 \mathrm{~A}$ and $\mathrm{B}$, the expression levels of mature miR-143 in CNE-1 and CNE-2Z cells transfected with miR-143 mimics were increased in a dose-dependent manner, compared with those in the cells transfected with NC miRNA $72 \mathrm{~h}$ after transfection. The CCK-8 assay showed a significant reduction of cell proliferation following transfection with $5 \mathrm{nM}$ miR-143 in comparison with NC miRNA at 48 and $72 \mathrm{~h}$ in the two cell lines $(\mathrm{P}<0.05$ at $48 \mathrm{~h}$ and $\mathrm{P}<0.01$ at $72 \mathrm{~h}$; Fig. $3 \mathrm{C}$ and $\mathrm{D})$. These results suggest that miR-143 significantly inhibits the proliferation of NPC 
A

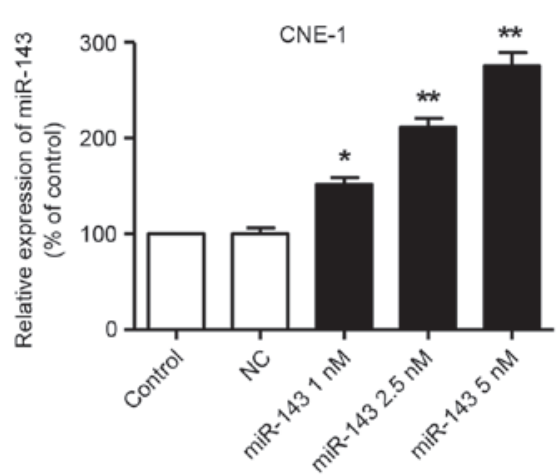

C

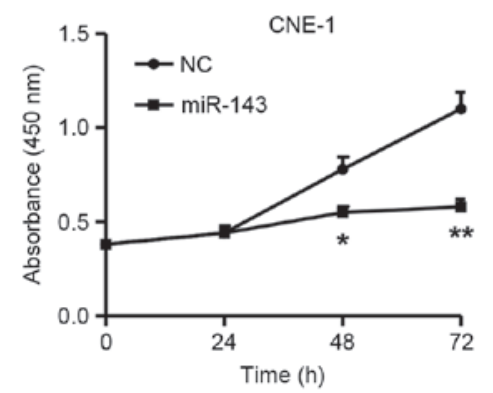

B

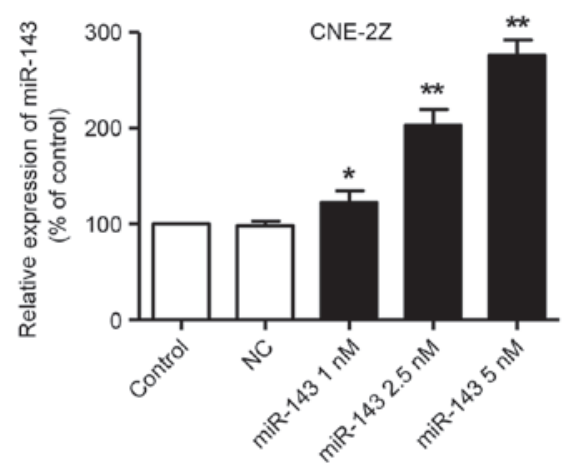

D

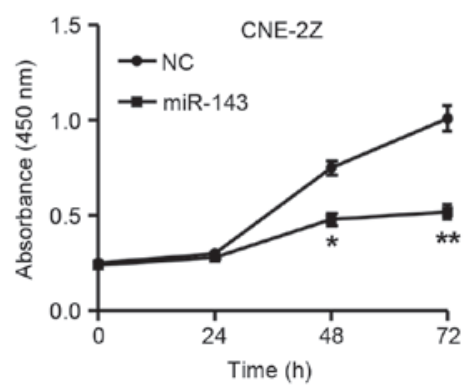

Figure 3. Enforced expression of miR-143 inhibits cellular proliferation of nasopharyngeal carcinoma. The expression levels of miR-143 were significantly upregulated at $72 \mathrm{~h}$ after transfection in (A) CNE-1 and (B) CNE-2Z cells, as assessed by reverse transcription-quantitative polymerase chain reaction. (C and D) CNE-1 and CNE-2Z cells were transfected with $5 \mathrm{nM}$ miR-143 and the proliferation of the cells was determined by Cell Counting kit-8 assay. Cell numbers were significantly decreased in the (C) CNE-1 and (D) CNE-2Z cells at 48 and $72 \mathrm{~h}$ after transfection. ${ }^{*} \mathrm{P}<0.05,{ }^{* *} \mathrm{P}<0.01$ vs. the NC group. NC, scrambled control.

A

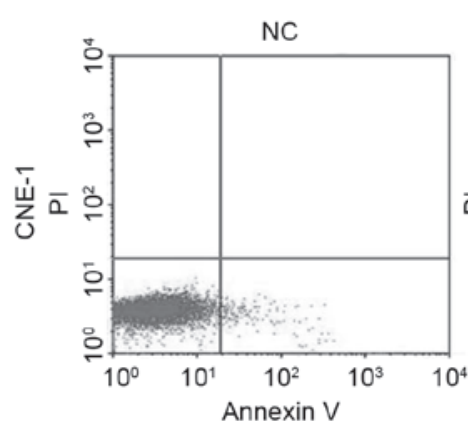

C

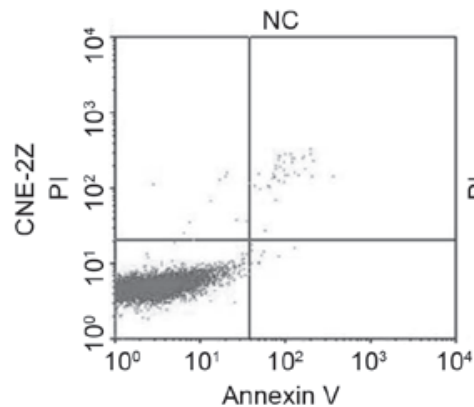

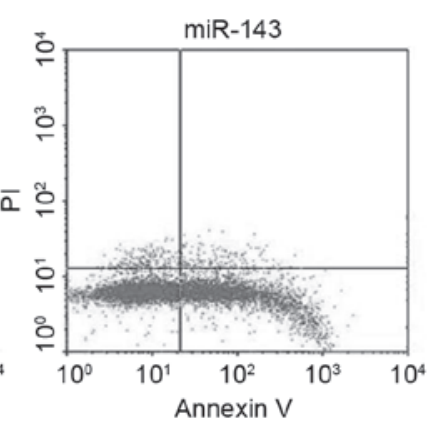

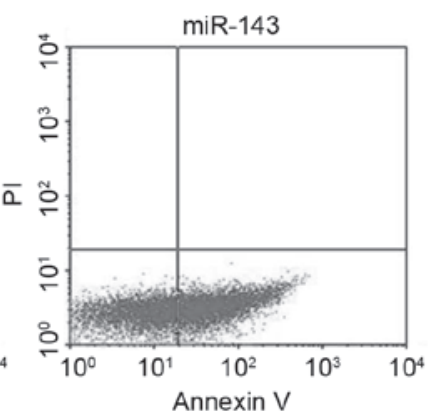

B
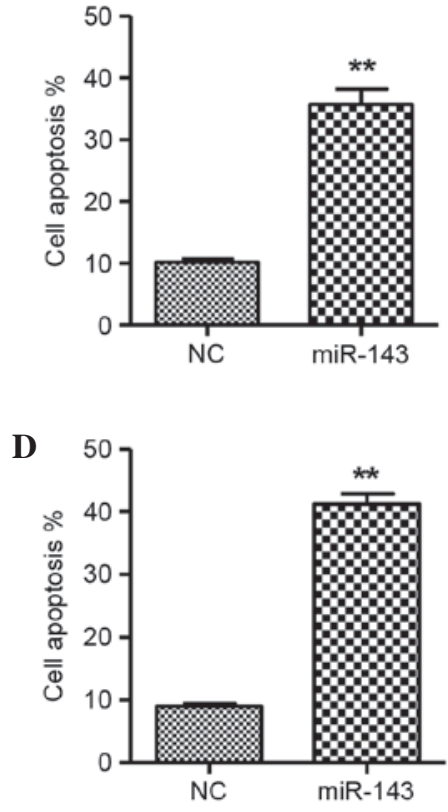

Figure 4. miR-143 induces apoptosis of nasopharyngeal carcinoma cells. Cell apoptosis was analyzed by flow cytometry at $72 \mathrm{~h}$ after transfection with $5 \mathrm{nM}$ miR-143. (A) Flow cytometry results for CNE-1 cells; (B) the proportion of apoptotic cells in the miR-143 group (35.67 $\pm 2.43 \%$ ) was significantly upregulated compared with that in the NC miRNA group $\left(10.16 \pm 0.51 \% ;{ }^{* *} \mathrm{P}<0.01\right)$. (C) Flow cytometry results for CNE-2Z cells revealed a similar trend; (D) the proportion of apoptotic cells in the miR-143 group $(41.23 \pm 0.73 \%)$ was significantly upregulated compared with that in the NC miRNA group $\left(9.00 \pm 0.75 \%\right.$; ${ }^{* *} \mathrm{P}<0.01$ vs. the NC group). NC, scrambled control; PI, propidium iodide.

cells. Moreover, flow cytometric analysis revealed that the overexpression of miR-143 resulted in a significant increase in the apoptosis of CNE-1 and CNE-2Z cells (Fig. 4), indicating that miR-143 may lead to apoptosis. 
A

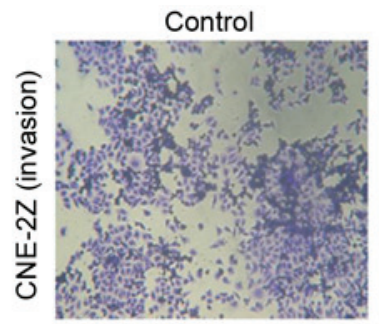

C

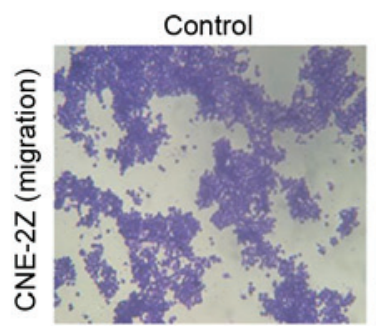

NC

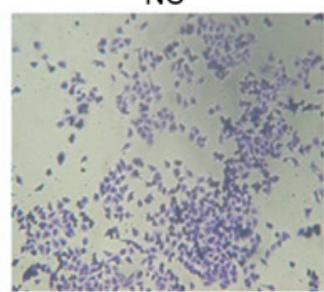

NC

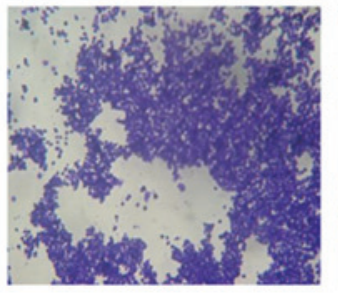

miR-143

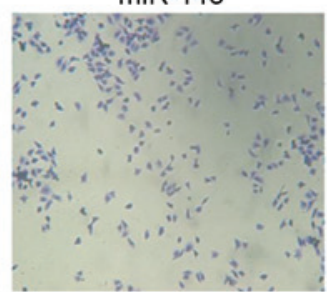

miR-143

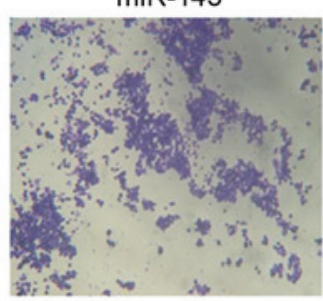

B

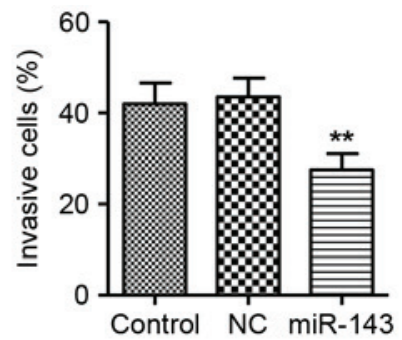

D

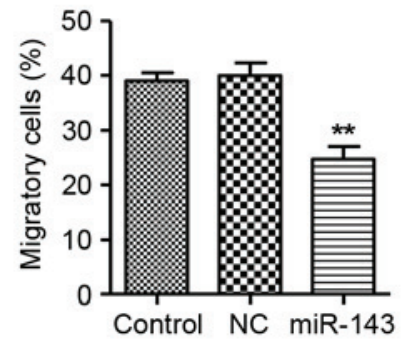

Figure 5. Effects of miR-143 on the invasion and migration of CNE-2Z cells. Cells were transfected with $5 \mathrm{nM}$ miR-143, and the numbers of CNE-2Z cells migrating through a microporous membrane were counted at $48 \mathrm{~h}$ after transfection. (A) Cell invasion assay of CNE-2Z cells after transfection. (B) The numbers of invasive cells were significantly decreased in the miR-143 group compared with the NC miRNA group. ${ }^{*}<0.05$ vs. the NC group. (C) Cell migration assay of CNE-2Z cells after transfection. (D) The numbers of migratory cells were significantly decreased in the miR-143 group compared with the NC miRNA group. ${ }^{* *} \mathrm{P}<0.01$ vs. the NC group. NC, scrambled control.
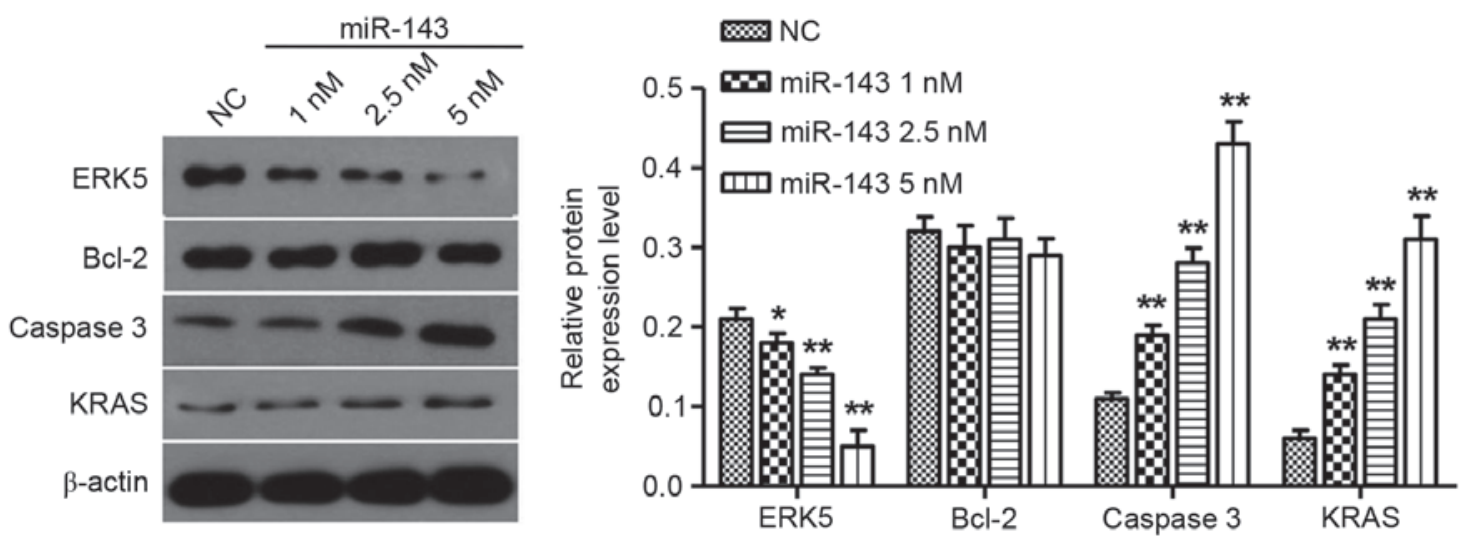

Figure 6. Expression of miR-143 candidate targets at $72 \mathrm{~h}$ after transfection in CNE-2Z cells, as assessed by western blotting. Protein expression levels of ERK 5 were reduced and those of caspase- 3 and KRAS were increased in a dose-dependent manner, while Bcl- 2 was not affected. ${ }^{*} \mathrm{P}<0.05$, ${ }^{* *} \mathrm{P}<0.01$ vs. the $\mathrm{NC}$ group. NC, scrambled control; ERK5, extracellular-signal-regulated kinase 5; Bcl-2, B-cell lymphoma 2; KRAS, Kirsten rat sarcoma viral oncogene homolog.

miR-143 inhibits NPC cell invasion and migration. In the invasion assay, the invasive rate of the NC miRNA group of CNE-2Z cells was $43.53 \%$ at $48 \mathrm{~h}$ after transfection. However, the invasive rate of CNE-2Z cells was significantly decreased by transfection with miR-143 $(27.56 \%$ at $48 \mathrm{~h}$ after transfection; Fig. 5A and B), compared with the CNE-2Z cells without miR-143 transfection. No significant difference between the NC miRNA and untreated groups was observed.

In the migration assay, the migratory rate of $\mathrm{CNE}-2 \mathrm{Z}$ cells in the NC miRNA group was $39.93 \%$ at $48 \mathrm{~h}$ after transfection. However, the migratory rate of CNE- $2 \mathrm{Z}$ cells was significantly decreased by transfection with miR-143 (24.7\% at $48 \mathrm{~h}$ after transfection; Fig. 5C and D) compared with the NC miRNA group. There was no evident difference between the NC miRNA and the untreated groups.

miR-143 inhibits ERK5 and promotes caspase 3 and KRAS expression in NPC cells. It has been reported that miR-143 targets the expression of ERK5 and Bcl-2 in prostate and cervical cancer $(18,19)$. To further investigate the targets of miR-143 in NPC, the expression levels of ERK5, KRAS, caspase 3 and Bcl-2 in CNE-2Z cells following miR-143 transfection were explored. The ERK5 protein levels were significantly reduced in a dose-dependent manner $72 \mathrm{~h}$ after miR-143 transfection, but caspase 3 as well as KRAS expression levels were increased in a dose-dependent manner $72 \mathrm{~h}$ after miR-143 transfection. Notably, overexpression of miR-143 did not have an impact on Bcl-2 protein expression (Fig. 6).

\section{Discussion}

miRNAs are regarded as important regulators involved in the regulation of protein post-transcription and can function as either tumor suppressors or promoters in cancer depending on the specific genes they target, and the abnormal expression of miRNAs may contribute to human carcinogenesis $(20,21)$. 
miR-143 is downregulated in various human malignancies, such as colon (10), gastric (11) and prostate cancer (22). In the present study, the expression levels of miR-143 in NPC tissues and matched normal tissues were examined, and it was found that miR-143 expression levels were significantly lower in NPC tissues than in normal tissues. In addition, the results also demonstrated that the downregulation of miR-143 expression was associated with later clinical cancer stages and lymph node metastasis in patients with NPC.

To the best of our knowledge, this is the first study to report that the overexpression of miR-143 contributes to the inhibition of cell proliferation, invasion and migration, and to apoptosis in NPC. In agreement with these findings, previous reports showed that miR-143 is associated with bone metastasis of prostate cancer (22) and invasion in esophageal squamous cell carcinoma (23). Clinical data in the present study indicate that miR-143 may function as a metastatic suppressor by inhibiting cell invasion and migration and inducing apoptosis, which affects multiple cellular processes, including carcinogenesis, invasion and lymph node metastasis, vital for the development and progression of cancer.

miRNAs target various genes involved in multiple cellular signaling pathways. miR-143 has been shown to downregulate Bcl-2 and KRAS in cervical cancer, osteosarcoma and colon cancer (24-26). In addition, miR-143 has been reported to regulate the 3 ' untranslated region of fascin actin-bundling protein 1 in esophageal cancer cells $(27,28)$. However, little is known about the effects of miR-143 on these targets in NPC. The results of the present study demonstrated that different doses of miR-143 reduced ERK5 protein levels and increased caspase 3 and KRAS expression levels in a dose-dependent manner, but the Bcl-2 level was not affected. The ERK5 protein is a protein kinase of the mitogen-activated protein kinase family, involved in the signaling processes downstream of various receptors. In addition, it has been indicated to be involved in sustaining cell proliferation, resisting cell apoptosis and promoting metastasis in a variety of malignancies $(29,30)$. The overexpression of miR-143 has been demonstrated to inhibit cell growth through the reduction of ERK5 expression in colon cancer, esophageal cancer cells and adipocytes (24-32). Caspase 3 is a member of the cysteine-aspartic acid protease (caspase) family. Sequential activation of caspases plays a central role in the execution-phase of cell apoptosis. A previous study showed that the overexpression of miR-143 was associated with decreased expression levels of $\mathrm{Bcl}-2$ and increased caspase 3 activation in human colon cancer (24). By contrast, the expression of Bcl-2 was not significantly affected by miR-143 overexpression, suggesting that the targets of miR-143 differed between different cancers. The findings of the present study provide evidence that miR-143 may function as a tumor suppressor in NPC by inhibiting ERK5 protein expression and promoting caspase 3 and KRAS expression.

In conclusion, this study has shown that miR-143 is frequently decreased in NPC tissues and cells and acts as a potential tumor suppressor in NPC. miR-143 represses ERK 5 expression and promotes caspase 3 and KRAS expression, which may play a role in NPC progression. Therefore miR-143 may serve as a biomarker and therapeutic target for NPC.

\section{References}

1. Hildesheim A and Levine PH: Etiology of nasopharyngeal carcinoma: A review. Epidemiol Rev 15: 466-485, 1993.

2. Feng BJ, Huang W, Shugart YY, Lee MK, Zhang F, Xia JC, Wang HY, Huang TB, Jian SW, Huang P, et al: Genome-wide scan for familial nasopharyngeal carcinoma reveals evidence of linkage to chromosome 4. Nat Genet 31: 395-399, 2002.

3. Sobin LH and Fleming ID; Union Internationale Contre le Cancer and the American Joint Committee on Cancer: TNM classification of malignant tumors, fifth edition (1997). Cancer 80: 1803-1804, 1997.

4. Wang J, Guo LP, Chen LZ, Zeng YX and Lu SH: Identification of cancer stem cell-like side population cells in human nasopharyngeal carcinoma cell line. Cancer Res 67: 3716-3724, 2007.

5. Lee YS and Dutta A: MicroRNAs in cancer. Annu Rev Pathol 4: 199-227, 2009.

6. Li G, Wu Z, Peng Y, Liu X, Lu J, Wang L, Pan Q, He ML and Li XP: MicroRNA-10b induced by Epstein-Barr virus-encoded latent membrane protein-1 promotes the metastasis of human nasopharyngeal carcinoma cells. Cancer Lett 299: 29-36, 2010.

7. Deng M, Tang H, Zhou Y, Zhou M, Xiong W, Zheng Y, Ye Q, Zeng X, Liao Q, Guo X, et al: miR-216b suppresses tumor growth and invasion by targeting KRAS in nasopharyngeal carcinoma. J Cell Sci 124: 2997-3005, 2011.

8. Wong TS, Man OY, Tsang CM, Tsao SW, Tsang RK, Chan JY, Ho WK, Wei WI and To VS: MicroRNA let-7 suppresses nasopharyngeal carcinoma cells proliferation through downregulating c-Myc expression. J Cancer Res Clin Oncol 137: 415-422, 2011.

9. Xia H, Ng SS, Jiang S, Cheung WK, Sze J, Bian XW, Kung HF and Lin MC: miR-200a-mediated downregulation of ZEB2 and CTNNB1 differentially inhibits nasopharyngeal carcinoma cell growth, migration and invasion. Biochem Biophys Res Commun 391: 535-541, 2010.

10. Ng EK, Tsang WP, Ng SS, Jin HC, Yu J, Li JJ, Röcken C, Ebert MP, Kwok TT and Sung JJ: MicroRNA-143 targets DNA methyltransferases 3A in colorectal cancer. Br J Cancer 101: 699-706, 2009

11. Takagi T, Iio A, Nakagawa Y, Naoe T, Tanigawa N and Akao Y: Decreased expression of microRNA-143 and -145 in human gastric cancers. Oncology 77: 12-21, 2009.

12. Osaki M, Takeshita F, Sugimoto Y, Kosaka N, Yamamoto Y, Yoshioka Y, Kobayashi E, Yamada T, Kawai A, Inoue T, et al: MicroRNA-143 regulates human osteosarcoma metastasis by regulating matrix metalloprotease-13 expression. Mol Ther 19: 1123-1130, 2011.

13. Noguchi S, Yasui Y, Iwasaki J, Kumazaki M, Yamada N, Naito S and Akao Y: Replacement treatment with microRNA-143 and -145 induces synergistic inhibition of the growth of human bladder cancer cells by regulating PI3K/Akt and MAPK signaling pathways. Cancer Lett 328: 353-361, 2013.

14. Zhang J, Sun Q, Zhang Z, Ge S, Han ZG and Chen WT: Loss of microRNA-143/145 disturbs cellular growth and apoptosis of human epithelial cancers by impairing the MDM2-p53 feedback loop. Oncogene 32: 61-69, 2013.

15. Zhang X, Liu S, Hu T, Liu S, He Y and Sun S: Up-regulated microRNA-143 transcribed by nuclear factor kappa B enhances hepatocarcinoma metastasis by repressing fibronectin expression. Hepatology 50: 490-499, 2009.

16. Xu YF, Li YQ, Guo R, He QM, Ren XY, Tang XR, Jia WH, Kang TB, Zeng MS, Sun Y, et al: Identification of miR-143 as a tumour suppressor in nasopharyngeal carcinoma based on microRNA expression profiling. Int J Biochem Cell Biol 61: 120-128, 2015

17. Livak KJ and Schmittgen TD: Analysis of relative gene expression data using real-time quantitative PCR and the 2(-Delta Delta C(T)) Method. Methods 25: 402-408, 2001.

18. Clapé C, Fritz V, Henriquet C, Apparailly F, Fernandez PL, Iborra F, Avancès C, Villalba M, Culine S and Fajas L: miR-143 interferes with ERK5 signaling, and abrogates prostate cancer progression in mice. PloS One 4: e7542, 2009.

19. Liu L, Yu X, Guo X, Tian Z, Su M, Long Y, Huang C, Zhou F, Liu M, Wu X and Wang X: miR-143 is downregulated in cervical cancer and promotes apoptosis and inhibits tumor formation by targeting Bcl-2. Mol Med Rep 5: 753-760, 2012.

20. Zhang Y, Wang Z, Chen M, Peng L, Wang X, Ma Q, Ma F and Jiang B: MicroRNA-143 targets MACC1 to inhibit cell invasion and migration in colorectal cancer. Mol Cancer 11: 23, 2012. 
21. Zhu S, Wu H, Wu F, Nie D, Sheng S and Mo YY: MicroRNA-21 targets tumor suppressor genes in invasion and metastasis. Cell Res 18: 350-359, 2008.

22. Peng X, Guo W, Liu T, Wang X, Tu X, Xiong D, Chen S, Lai Y, Du $\mathrm{H}$, Chen $\mathrm{G}$, et al: Identification of miRs-143 and -145 that is associated with bone metastasis of prostate cancer and involved in the regulation of EMT. PloS One 6: e20341, 2011.

23. Hiyoshi Y, Kamohara H, Karashima R, Sato N, Imamura Y, Nagai Y, Yoshida N, Toyama E, Hayashi N, Watanabe M and Baba $\mathrm{H}$ : MicroRNA-21 regulates the proliferation and invasion in esophageal squamous cell carcinoma. Clin Cancer Res 15 1915-1922, 2009.

24. Borralho PM, Simões AE, Gomes SE, Lima RT, Carvalho T, Ferreira DM, Vasconcelos MH, Castro RE and Rodrigues CM: miR-143 overexpression impairs growth of human colon carcinoma xenografts in mice with induction of apoptosis and inhibition of proliferation. PLoS One 6: e23787, 2011.

25. Chen X, Guo X, Zhang H, Xiang Y, Chen J, Yin Y, Cai X, Wang K, Wang G, Ba Y, et al: Role of miR-143 targeting KRAS in colorectal tumorigenesis. Oncogene 28: 1385-1392, 2009.

26. Zhang H, Cai X, Wang Y, Tang H, Tong D and Ji F: microRNA-143, down-regulated in osteosarcoma, promotes apoptosis and suppresses tumorigenicity by targeting Bcl-2. Oncol Rep 24: 1363-1369, 2010.
27. Liu R, Liao J, Yang M, Sheng J, Yang H, Wang Y, Pan E, Guo W, $\mathrm{Pu}$ Y, Kim SJ and Yin L: The cluster of miR-143 and miR-145 affects the risk for esophageal squamous cell carcinoma through co-regulating fascin homolog 1. PloS One 7: e33987, 2012.

28. Wu BL, Xu LY, Du ZP, Liao LD, Zhang HF, Huang Q, Fang GQ and Li EM: MiRNA profile in esophageal squamous cell carcinoma: Downregulation of miR-143 and miR-145. World J Gastroenterol 17: 79-88, 2011.

29. Drew BA, Burow ME and Beckman BS: MEK5/ERK5 pathway: The first fifteen years. Biochim Biophys Acta 1825: 37-48, 2012.

30. Lochhead PA, Gilley R and Cook SJ: ERK5 and its role in tumour development. Biochem Soc Trans 40: 251-256, 2012.

31. Ni Y, Meng L, Wang L, Dong W, Shen H, Wang G, Liu Q and Du J: MicroRNA-143 functions as a tumor suppressor in human esophageal squamous cell carcinoma. Gene 517: 197-204, 2013.

32. Esau C, Kang X, Peralta E, Hanson E, Marcusson EG, Ravichandran LV, Sun Y, Koo S, Perera RJ, Jain R, et al: MicroRNA-143 regulates adipocyte differentiation. J Biol Chem 279: 52361-52365, 2004. 